\title{
The Moral Threat of Compartmentalization: Self, Roles and Responsibility
}

\section{Cécile Rozuel}

\author{
Contact: \\ Dr. Cécile Rozuel \\ Institute for Socio-Management \\ Stirling Management School \\ University of Stirling \\ Stirling FK9 4LA, UK \\ Email: cecile.rozuel@stir.ac.uk
}

***Published in 2011 in the Journal of Business Ethics, 102(4), pp.685-697***

\begin{abstract}
Although most of us understand and accept that we play different roles in different settings, the moral implications of an unquestioned role-based world are serious. The prevalence of roles at the expense of 'real' people in organisations jeopardizes our ability to exercise full moral agency and ascribe moral responsibility, because 'we were only fulfilling our role obligations'. This reasoning does not sustain ethical scrutiny however because individuals are always present behind the role, though they may lack awareness of their ability to choose and act as fully-fledged individuals. The paper argues that moral responsibility requires us to move away from a role-based life game which leads us to compartmentalize and forget who we are and what we value at a significant cost. On the contrary, an understanding of the process of compartmentalization and a greater awareness of the complex yet holistic nature of the self contribute to furthering moral integrity and responsibility.
\end{abstract}

Keywords: Compartmentalization, Jung, Moral Agency, Persona, Responsibility, Role, Self

\section{Introduction}

“Jusqu'ici j'ai vu beaucoup de masques, quand verrai-je des visages d'hommes ?"

In his novel La Nouvelle Héloïse (1761/1999), Jean-Jacques Rousseau thus depicted the prevalence of masks over actual human faces, denouncing the wide-spread pretence in which many of his contemporaries complacently revelled. In a society where one could rise to the 
top as easily as one could fall into disgrace, strategy and deception seemed necessary - albeit if you belonged, or cared to belong to the élite. A century earlier, Jean de La Bruyère had captured the ridicule of those characters ("caractères") who try so hard to project what they are not, convinced that this is the key to achieving recognition, status and gaining favours (1688/1975). Inasmuch as we mock these attempts, they remain a consistent pattern of behaviour which we often ourselves embrace, admittedly or not. Whether this is a morally wise choice is however questionable, both at a personal and social level. Indeed, how are we to hold a mask accountable for its actions? Equally, how can a society made up of masks and pretenders be held accountable for what it produces? Masks and pretenders, by definition, are not real. Yet accountability requires an actual presence, a constant reality upon which we can impose our moral judgement.

Today's workplaces are no different from the social reality pictured by La Bruyère or Rousseau. Actually, people at work are encouraged to embody certain values that suit the corporate credo, to wear the company's mask or uniform. Rarely do we see human faces, but all too often do we encounter 'salespeople', 'account managers' or 'bankers'. If anything, our mindsets have accepted that 'business is business' and leaves no place for something else. Management studies have contributed to reinforcing the belief that organisations are composed of 'managers' - as if managers were a species in their own right. The fact is, however, that managers are first and foremost people, individual human beings who happen to work as managers. Managers or any type of 'organisational actors' are not chameleons deprived of a unique identity and changing colours to suit the setting, the performance expectations or simply to get the job done. They are primarily individuals who possess a self, a soul, and an inherently complex psyche. 
In a rather paradoxical twist, organisational studies have demonstrated a growing interest in anthropomorphising organisations and exploring the soul of corporations, whilst organisational members have been increasingly reduced to cogs in a complex structure or in a system with a life of its own. The moral implications of this shift are particularly significant, because people become absent from the moral equation, being replaced by 'roles' or 'masks' or 'uniforms'. Nowadays, corporations feel, think, act - and people are nowhere to be seen, except maybe at the end of the chain, where the dire consequences of an impersonal system are felt most acutely. But organisations would not exist if people hadn't created them in the first place, and didn't work in them on a daily basis.

People who compose work organisations are complex, singular and individual. They are complex because their personality is not one-piece-made, but rather a collection of "petits moi" (Aïssel, 2005) or small egos that interact with one another, sometimes contradicting one another (White, 1991). They are also singular because of the unique integration and expression of these small egos to form a self that characterizes the person as an individual. The self represents not just our personality but identifies our whole beingness, our spirit (Layder, 2004).

Our passions, our emotions, our rational calculations, our habits all influence our behaviour and bring to light our contradictions. For instance, when the "material ego" is little concerned with our feelings but acts on automatisms, the "reactive ego" thrives on emotions and excessive subjectivity, if not hardcore prejudices (Aïssel, 2005). It is very likely that the material ego will entice us to act in a very different way than the reactive ego would, creating a conflict within ourselves. These conflicts are trivial when they deal with minor decisions of everyday life; they are more serious when they involve a decision of a moral nature. The 
moral issue is two-fold: either the person voluntarily shuts down the various egos to allow only one to direct her/his behaviour, or (s)he unconsciously identifies with one ego and assume it represents her/his whole being. In both cases, the person compartmentalizes. However in the first instance, the person chooses to withdraw parts of her/himself and to let one aspect prevail, out of comfort or out of interest; whilst in the second case, the person is not aware that (s)he is fragmenting her/his personality, hence losing sight of who (s)he actually is.

Consequently, awareness of our natural tendency to fragment and to compartmentalize our personality is a necessary endeavour to foster good moral standards (Gotsis and Kortezi, 2008). Acknowledgement of the inner moral tensions inherent to every individual is essential to rediscover the self and achieve a state of wholeness, as Carl Jung's individuation process clearly exemplifies (Jung, 1958/2002). Denial of our contradictions and rejection of parts of our psychic experiences only drive us further away from our self, which actually represents our true identity. Therefore identifying our sub-personalities, that is the small egos that pressurize and disturb our quest for the whole self, is the key to unleashing our potential (Ferrucci, 2004). This is important not only to maintain psychological balance, but also to further ethical behaviour. Indeed the compartmentalized person may, consciously or not, censor the moral values, aspirations, feelings and emotions that are deemed inappropriate and irrelevant to a certain context (e.g. the workplace), thereby creating a moral void by disengaging the moral responsibility of her/his self (i.e. who they really are).

The paper first discusses the idea of roles and examines some ethical implications. It then turns to exploring the phenomenon of compartmentalization, its ethical relevance and its moral effects in context. Evidence of the pervasiveness of compartmentalization in various 
professions as well as in management receives close attention. The paper then argues that wholeness and integrity of self are better warrant of sound ethical behaviour than compartmentalization. Using insights from the Jungian process of individuation, the paper concludes that acknowledging the centrality of the self in our behaviour is necessary and essential to fostering morally consistent and admirable behaviour.

\section{Roles and Self: Whose Moral Responsibility?}

The concept of compartmentalization is familiar to psychologists and social psychologists. To compartmentalize means to divide something into distinct and separate sub-sections. Psychological compartmentalization thus refers to the process through which we isolate and separate certain aspects of our personality from the rest of our personality or from our core self. Akin to "blind spots", compartmentalization consists in "pigeonholing one's life into rigid and exclusive categories" (Monte, 1977, p. 665). This phenomenon flows from the fact that we arguably embrace multiple identities through our life, each being defined and influenced by the groups we interact with or the roles we perceive we ought to or wish to enact (Pratt and Foreman, 2000). We are not 'one self' but a "multiple self” (Elster, 1986), constantly managing or juggling with our various self-aspects to suit the social expectations and our own built-in expectations. Social psychology has mapped this process as role-taking or role-playing. Goffman (1959) in particular has articulated the view that life is a representation where we are all prompted to perform certain roles, taking cues from the audience and fellow performers, managing the transition from backstage to front-stage, hiding our self effectively behind the characters we play. The self evolves along with the roles the person enacts, construed as the fruit of social interaction. 
The role framework has fuelled discussion on professional ethics as opposed to personal ethics. Some of the main questions raised include the moral responsibility ascribed to a professional role, the content of a professional ethos, and the articulation of personal values with values attached to a professional role. Such line of argument is particularly prevalent in business practice, where people often claim they act as representatives of an organisation rather than as individuals free to make their own decisions. Consequently, their moral responsibility appears heavily mitigated in so far as they do not create nor define the roles they are requested to endorse. This conclusion, however, is inaccurate. As Flores and Johnson (1983, p. 542-3) point out:

"First, individuals freely choose to become members of a collective organization and as such they voluntarily assume the roles they play. Even admitting the pressures that may force a person to accept a particular job, it is always possible to resign [...].

Second, though the individual's actions are generally constrained by the ends of the organization, individuals usually benefit personally from the profit or achievement of the organization, and thus they never act wholly impersonally. [...] One must distinguish between the requirements imposed on the individual by the role and the individual's willingness to fulfil these requirements. [...]

Finally, though there are constraints on individual action, individuals can bring various moral qualities of their own to the positions they fill."

Flores and Johnson (1983) thus insist that an individual's action is ultimately commanded by his or her free will rather than by a role. In other words, people are more than roles; they are truly individuals and "only individuals can choose to act". (Flores and Johnson, 1983, p. 543). Apprehending what defines us as individuals is complex however. The role theory actually questions the existence of a stable, enduring and individual self outside the scope of social interaction: although we refer to someone's personality or identity, there is no sense of actual 
unity (although there may be a sense of conceptual unity whereby we add up the various roles an individual performs in his or her life-time and label the grand total their 'identity'). For role theorists the self, understood as the core of our identity, is ever changing, in formation. This position however raises a significant moral issue: if the core of our identity is multiple and constantly changing, what or who bears the moral responsibility for our actions?

Ascribing moral responsibility requires identifying a somewhat stable subject who is directly implicated in and affected by the actions taken. As such, a role cannot be ascribed moral responsibility because it merely is a social construction; on the other hand, the role bearer has a direct moral responsibility in the actions taken whilst performing the role. Yet if the role bearer's core identity is itself ever changing, influenced by the roles enacted and the social expectations they carry, we are left without any stable element qualified to bear moral responsibility. In other words, either we ascribe only relative moral agency and moral autonomy - which considerably diminishes the value of moral responsibility - or we accept the fact that our core identity is composed of a stable element located outside the scope of influence of social interaction. As Vice (2003, p. 105) notices: "If we see ourselves purely in terms of roles, we both risk bad faith in the Sartrean sense - mauvaise foi - as well as losing sight of the individuality of persons.[...] And it is arguably a sign of maturity to outgrow 'role-playing', to stop defining ourselves essentially with any role we may happen to take on and to become comfortable with or resigned to the kind of person we broadly are and to our inescapable limitations."

This maturity is essentially what ' $\mathrm{J}$ ' lacks in MacIntyre's analysis of the pernicious influence of social structures on individual morality (MacIntyre, 1999). ' $\mathrm{J}$ ' is introduced as a scrupulously obedient role-performer who does not feel responsible for the consequences of 
his actions because he only fulfils his duties in accordance with the prevalent social norms of good behaviour. If ' $\mathrm{J}$ ' works as a railroad traffic supervisor, and the society he knows and lives in primarily values straight obedience to one's duty without asking questions, MacIntyre asks on what grounds we can or should hold ' $\mathrm{J}$ ' responsible for participating in transporting Jews to concentration camps (1999, p. 312). The answer, for MacIntyre, lies in the characteristically human, rational ability to step outside one's sphere and one's role to examine with a critical eye the social structures and values that influence our behaviour so extensively. As moral agents, we are expected to scrutinize our identity and all those factors that shape our character and our moral expectations. MacIntyre (1999, p. 321) insists that we should seek to establish "milieus" whereby we can question the traditionally unquestioned standards, assumptions, traditions, values. The conflicts that emerge from confronting one's standards with potentially different standards are what gives substance to the practice of the virtues (MacIntyre, 1999).

\section{The Moral Value of a Whole Self}

If roles jeopardize moral agency, moral autonomy and moral responsibility, we are left in need of a stable, core self which could provide a safe anchor for unfolding our individuality and enhancing our moral agency. The meaning of the self concept is manifold, ranging from a mechanistic view to a spiritual aspiration. The self has been perceived as an ego-construction or ego-projection, a product of dynamic psychic processes, the locus of psychic activity, the sum of the "small egos" that compose our personality, or the essence of beingness in the form of a "higher or greater self" (Doron and Parot, 1991; Hubback, 1998; Aïssel, 2005; Colman, 2008). Most often, the self is conceived "as an information processing network, which is multi-faceted, dynamic and hierarchical. It acts to guide behaviour through self-regulation, and guides information processing in relation to self-relevant information." (Moss and Carr, 
2004, p. 738). However the prevalence of such mechanistic view fails to account for the specificity of being an individual and the spiritual dimension of existence.

More holistic approaches to the self-concept acknowledge both the centrality of the self and its relativity in connection with a greater whole. The self, sometimes labelled inner self, is the epitome of our individuality, the essence of beingness, and the locus of both psychic activity and spiritual advancement. Even though our personality stands fragmented by small egos, personal growth involves the coming-to-consciousness of our fragmented nature and the working towards the state of a whole self, given that the self contains the totality of our being (Guillory, 2001; Zsolnai, 2004). MacIntyre (1999, p. 325-6) conceives of a divided self which necessarily lacks integrity and constancy for these are attributes of sphere-bounded roles. The divided self must be adaptable, flexible, capable of withstanding conflict and changing viewpoints, since its purpose is to step outside the roles and scrutinize their content. MacIntyre further states that what the divided self lacks, it lacks willingly and there lies its moral agency. The "active refusals and denials" to embrace indiscriminately the prevailing norms attached to a role imply a choice from the self's part to indeed adopt such and such norms within such and such context, whilst playing such and such role (MacIntyre, 1999, p. 327). The divided self thus becomes "co-author" of its actions whilst performing a role: one cannot say (s)he did not know, because part of her/himself did know and did make a choice to dutifully discharge one's role obligations (MacIntyre, 1999).

Such negative conception of the self (in the sense of defining the self through what it lacks as opposed to what it does possess) is however limiting if our purpose is to nurture greater moral exemplarity. The self is not necessarily divided, but is on the contrary unity. The self as unity not only facilitates the transition between roles, but also gives access to other choices, other 
roles, more refined, more authentic. A holistic self does not lack but actually need integrity and constancy, for there lies moral excellence.

Few psychologists have captured the spiritual nature of the self as comprehensively as Carl Gustav Jung. Jung pictures the psyche as comprising both personal and collective unconscious elements. At the forefront of consciousness stands the persona, which shares a striking resemblance with what we refer to as social roles. The persona is a "false self", a mask worn to suit societal expectations or ego-driven ambitions (Hill, 2000). More importantly, the persona results from a personal interpretation of collective expectations, hereby fundamentally different from the expression of one's individuality. The persona is embraced by the ego, centre of consciousness and key to the development of a relatively stable personality. Although crucial to leading a healthy conscious life, the ego does not - and should not - dominate our relation to the external world. The self is the true subject of the whole psyche and prefigures the ego (Jung, 1969b, 1971). The Jungian conceptualisation of self partly derives from the Hindu perspective of "the divine Self within" (Crowley, 1998) and consists in "the experienceable and the inexperienceable (or the not yet experienced)" (Jung, 1971).

The self is by nature an archetype, a primordial image pertaining to our shared collective unconscious. The archetypal self symbolises wholeness, order, organisation and unification, and serves as an inner guide towards achieving maturity and self-realisation (Hall and Nordby, 1973). The ultimate life purpose is individuation, the process through which we uncover pieces of our unconscious, gain knowledge of the self, acknowledge our strengths and limitations and come to appreciate humanity at a deeper level (Sharp, 1991). Individuation itself is a moral endeavour inasmuch as the person embraces both his or her 
uniqueness - which carries their distinctive individual responsibility - and his or her belonging to an indivisible whole - pointing towards an all-encompassing responsibility as a human being. Becoming individuated affects one's personal moral responsibility: the more individuated a person, the freer the person is to make decisions. Jung (1971, p. 449) felt strongly against the surrendering of our individual status to a collective: “The more a man's life is shaped by the collective norms, the greater is his individual immorality." Individuation does not lead to an individualistic society however; rather, the more a person knows her/himself and embraces her/his individuality, the greater her/his awareness of an interconnectedness of everything, the greater her/his sense of belonging to the whole and the greater her/his appreciation of the community (s)he lives in.

Jung $(1958 / 2002,1969 b, 1971)$ warned that the process of individuation is painful and lengthy, but nonetheless essential to our psychic health and personal flourishing. The first step towards becoming a true individual would consist in identifying the persona and disassociating the ego from the persona in order to connect with the self. Awareness of the roles we play and the masks we wear is essential in the pursuit of increased authenticity. Yet we are often unable to readily connect with our self because our conscious ego has identified exclusively with the persona. This state of inflated ego thwarts self-knowledge and spiritual growth as the ego is overshadowed by a limited aspect of one's personality. The person becomes alienated from her/his self, experiencing tensions between the overbearing role and her/his essential nature (Hall and Nordby, 1973). These tensions may not be consciously acknowledged but nevertheless threaten the integrity of our psychic identity. A persona-led ego is a major manifestation of the phenomenon of compartmentalization. 


\section{Value of and Risks Associated with Compartmentalization}

Compartmentalization is not generally construed as a threat but rather as a normal process which helps us make sense of the world and cope with disruptions. Studies on psychological compartmentalization aim to depict how we organise knowledge of self (here self is understood in the traditional sense of the sum of multiple identities). Our knowledge of self is contextualised, that is "actively constructed by individuals who shape their own selfcategories and contexts as part of their general motivation to make sense of the world and to function adaptively within it." (Showers and Zeigler-Hill, 2007, p. 1182). Compartmentalization serves a clear purpose: "individuals construct contextualized selves that organize positive and negative beliefs about the self in a way that serves either implicit or explicit self-goals", notably self-esteem and long-term psychic and emotional stability (Showers and Zeigler-Hill, 2007, p. 1183). Showers and Zeigler-Hill (2007) thus identify instances of both positive and negative compartmentalization, which they contrast with state of integrative self-organisation.

Positive compartmentalization refers to a process through which individuals associate a specific identity with essentially positive qualities (e.g. 'as a parent, I am patient, kind, loving, energetic, confident' or 'as a manager, I am confident, trustworthy, efficient, ambitious'). Negative compartmentalization, on the other hand, illustrates the process through which individuals judge themselves harshly when they enact a certain role (e.g. 'when I meet people I don't know, I feel awkward, timid, inferior or irritable'). In contrast, instances of integrative self-organisation portray individuals who associate a mix of positive and negative traits with each role or identity they endorse. Showers and Zeigler-Hill's studies suggest that integrative self-organisation demand greater emotional and cognitive efforts. They argue that at first integration mitigates mood swings although it becomes increasingly difficult to sustain 
integration as time passes (Showers and Zeigler-Hill, 2007). Compartmentalization, however, would help in situations where people need to cope with bad experiences. The authors conclude that "compartmentalization may actually be an effective strategy as long as it successfully limits access to negative attributes" but they equally notice that greater integration might enable the person to project a more realistic picture of their environment and their closed ones, whilst encouraging greater authenticity in self-knowledge (Showers and Zeigler-Hill, 2007, p. 1194-5).

From a cognitive point of view, compartmentalization does not seem to be such a problem; it actually offers a solution for coping with extremely negative feelings or traumatic experiences. Yet compartmentalizing does not equate suppressing. Even if we can safely store in the back of our mind a particularly negative feeling so that it will not affect our behaviour and perception of self, the feeling remains present and real. We have not dealt with it; we have simply put it aside. We may no longer be affected by this feeling consciously, but our unconscious bears its marks. It usually happens that one event or one sentence during a casual conversation, sometimes with little or no connection to the situation or the feeling we worked hard to dissociate from, will immediately trigger an uneasiness reminding us that the original feeling remains, notwithstanding the amount of conscious efforts to suppress it. We do not forget because we cannot forget. The most compartmentalized person nevertheless stores all of her/his cognitive and affective experiences in her/his psyche, whether at the conscious or unconscious level.

Jung examined this phenomenon through the concept of complexes. A complex develops when we have failed to integrate the dual energy of a particular experience or thought. This energy is then captured by an archetype (possibly the shadow which is our primitive, darker 
side) and remains unprocessed. For example, I may think that I am a generally generous person and I consciously endeavour to act with generosity in everyday life. If one day a friend asks for my help, I would want to help her. Whilst processing my friend's request, I may feel that I answer 'Of course I'll help you' spontaneously; yet simultaneously, if ever so briefly, I also think 'I don't want to help you because I'd rather do something else that day'. This does not mean that I don't want to help my friend or that I am not a truly generous person; it simply means that I am not absolutely generous, in the sense that I never experience any restrictions with regards to my generosity. Of course I may not be aware of experiencing such restrictions.

If I don't acknowledge that I had the thought of not helping my friend, the psychic energy received by this thought remains unprocessed, whereby developing into a complex and nourishing my shadow. If I compartmentalize and think of myself as a generous person always willing to help others, my unprocessed reluctant thought might come and haunt me at a later stage - for example making me feel unusually irritated by my friend's behaviour, or making me sleep agitatedly the night before I am due to help my friend, so that I am very tired and cannot help as much as I would like to. Once the energy has been released, there is no escaping it, unless one consciously (and bravely!) acknowledges it and integrates it into her/his knowledge of self.

Jung (1969b, p. 76) stressed that it is critical for our own sanity to acknowledge our various experiences and integrate them accordingly, rather than to discard whatever does not fit our mental picture of ourselves:

"Unfortunately there can be no doubt that man is, on the whole, less good than he imagines himself or wants to be. Everyone carries a shadow, and the less it is embodied in the individual's conscious life, the blacker and denser it is. If an inferiority is conscious, one always 
has a chance to correct it. Furthermore, it is constantly in contact with other interests, so that it is continually subjected to modifications. But if it is repressed and isolated from consciousness, it never gets corrected, and is liable to burst suddenly in a moment of unawareness. At all events, it forms an unconscious snag, thwarting our most well-meant intentions."

Recognition of the shadow means acknowledging our imperfection; it also authorises a more conscious relationship with others to develop (Jung, 1958/2002, p. 73). Yet greater awareness cannot occur if the ego-consciousness is obscured by the persona. By compartmentalizing, the individual over-emphasizes aspects of her/his personality whilst discarding others. As a consequence, (s)he can neither rely on the strengths of an authentic individuality, nor maintain her/his moral and psychological integrity. Awareness of the complexities of self and of the reality of our evil tendencies is morally empowering. By removing the veil behind which we hide our shortcomings, we cease to fear what these might reveal to others and to ourselves, thereby taking charge of our character instead of being led by it. Jung (1969a, p. 10) thus summarises this difficult but critical moral and psychological task:

"It is often tragic to see how blatantly a man bungles his own life and the lives of others yet remains totally incapable of seeing how much the whole tragedy originates in himself, and how he continually feeds it and keeps it going. Not consciously, of course - for consciously he is engaged in bewailing and cursing a faithless world that recedes further and further into the distance. Rather, it is an unconscious factor which spins the illusions that veil his world. And what is being spun is a cocoon, which in the end will completely envelop him."

The failure of ' $\mathrm{J}$ ' to act as a moral agent also exemplifies the process of compartmentalization, which MacIntyre (1999, p. 322) defines as:

"the extent to which each distinct sphere of social activity comes to have its own role structure governed by its own specific norms in relative independence of other such spheres. Within each 
sphere those norms dictate which kinds of consideration are to be treated as relevant to decisionmaking and which are to be excluded."

Each individual learns to adapt to the specific norms and standards of the various spheres (s)he takes part in, from the workplace to the family life or sports activities. The prevalence of one particular set of norms as separated from the rest of one's life is accentuated by the fact that the individual will generally meet the same people within the same sphere. The motto that one should never mix work with family or friends illustrates how compartmentalization can so easily become a natural fact of life: I can be one person at work and an altogether different person at home because the people I interact with in the 'work sphere' never or rarely meet me within my 'family sphere' when I enact a different role with different values. The crucial moral lapse comes as the individual dissolves into her/his roles and forgets (s)he is more than the roles. (S)he equally forgets that others are more than just roles (MacIntyre, 1999). To possess a sense of wholeness as an individual self thus constitutes a pre-requisite to effective moral agency.

\section{Compartmentalization in the Workplace}

The compartmentalized person is not connected to the self, and this "absence to one's self" eventually threatens both moral judgement and moral behaviour (Terestchenko, 2008). Whenever the person is unconnected to the self, (s)he tends to switch off her/his conscience and 'act as' an agent of the system. The moral responsibility is nil because it is not the singular person but a non-distinctive agent who makes and implements the decisions (Terestchenko, 2007). Moral strength and moral consistency, on the contrary, are attributes of a whole person, that is a person who does not forget who (s)he is when (s)he steps into the office, and who equally understands that what (s)he does at work affects her/his life beyond the mere organisational boundaries. 
A few studies involving a variety of professions have provided instances of the pervasiveness of compartmentalization in the workplace and its subsequent moral cost. Pajak and Blase (1984) interviewed public-school teachers who gather in a bar after school to relax and socialise. Although primarily focused on the meaning of the bar setting to the teachers, Pajak and Blase's study provides many examples of the moral cost of compartmentalization. The majority of teachers believed they had to play a particular role in their workplace (teacher as an authoritative, emotionally distant figure) and used the bar setting to switch from their “professional self" to their "personal self". Compartmentalization was perceived as a solution to relieve the tension experienced when professional self and personal self conflict. The teachers did not necessarily endorse the distinctive professional role they eventually played; rather it seems that they perpetuated the institution's implicit requirements at a personal cost as they came to accept the role as part of their identity and celebrate compartmentalization as a pain-relief. Pajak and Blase (1984, p. 169) explain that: "This splitting of the teacher's identity is apparently activated by an attempt to protect the artificial social realities of the classroom and school from intrusions of the outside world. Not surprisingly, this manner of dealing with the situation seems to affect the teacher's perception of self and relationships with other teachers."

Although they do not use the term compartmentalization, Pajak and Blase (1984, p. 171) refer to the "absence of a person-role merger" which "can be seen both in teachers' greater unwillingness to maintain their professional roles in the community and in the inconsistencies between their privately held attitudes and beliefs and those required by their professional role." In other words, compartmentalization might lead to an alteration of the teachers' core moral beliefs when they 'perform' as teachers. Their self, locus of authenticity and lever of moral courage and moral strength, is disconnected so that they tend to accept behaviours or 
values they would otherwise disapprove of, should they be 'themselves'. Pajak and Blase's study also suggests that interacting with others as a self, that is as an individual person rather than as a role, is more beneficial overall. They remark that teachers built some strength by "talking in the barroom as people about job-related problems" so that although they resume their "impersonal professional role" back to school, they cope with work problems better (Pajak and Blase, 1984, p. 172). This might be so because role enactment prevents one from displaying personal distress or discomfort, therefore blocking authentic accounts of one's experience and limiting advice and change. Interacting as people, on the contrary, allows for more fruitful discussions and exchanges, greater awareness of one's strengths and possible insights of moral imagination (e.g. Werhane, 1999).

Kelly (1998) followed a group of graduate nurses and examined if and how they preserved their moral values whilst coping with the reality of work in a ward. She describes instances of rationalization as a means to adjust their personal expectations with their actual performance and the demands of their work environment. She states that: "Compartmentalization happens when nursing students, in moving from the worlds of academic education and hospital clinical practice, come to terms with 'two versions of nursing', each with its own standards and rules." (Kelly, 1998, p. 1135). The graduate nurses followed by Kelly experienced a six-stage basic psychological process which enabled them to adapt to their work reality: "vulnerability; getting through the day; coping with moral distress; alienation from self; coping with lost ideals; and integration of new professional self-concept.” (1998, p. 1137). The last three stages are characteristic of compartmentalization. They stress the moral cost one pays by endorsing a role which is perceived as a safeguard but which actually undermines one's moral integrity. 
Kelly (1998, p. 1140) notices that as the nurses realised that they cannot practice at their high standards, and that they fail to be the nurses they aspired to be, they rationalized until they created a revised professional identity: "Coping with the loss of ideals requires that one justify why one no longer does what once was valued." However rationalization here is a form of self-deception and the resulting professional identity is a social construction rather than a reflection of the self (Kelly, 1998, p. 1140-1). Kelly (1998) concludes her study emphasizing the moral distress caused by a misrepresentation of the reality of the work environment by student nurses; however significant, this aspect should not overshadow the fact that the graduate nurses ultimately compromised their high moral ideals to fit into their ward. Compartmentalization helped them cope with real-life, but their moral integrity and moral sensitivity were seriously weakened.

\section{Compartmentalization in Business}

Gioia's personal experience as a Problem Analyst for the Ford Motor Company sheds light onto the moral cost of compartmentalization in the business world. Gioia (1992, p. 379) joined the company as a fresh, critical and enthusiastic graduate with high hopes of changing an inconsiderate, indifferent or unethical business mindset. But he quickly found himself enmeshed in the corporate culture, where "to do the job 'well' there was little room for emotion. Allowing it to surface was potentially paralysing and prevented rational decisions about which cases to recommend for recall." (Gioia, 1992, p. 382). Gioia believes that he adopted scripts to manage the decision-making process which was central to his job as a manager responsible for recalls of faulty vehicles. Scripts are necessary to deal with multiple information and prioritise tasks, but they don't necessarily encourage "good decision making". It becomes "a default mode of organizational cognition" which allows otherwise morally aware people to overlook significant moral problems because they only analyse 
issues through existing scripts and are mentally incapable of spotting and dealing with unusual patterns (Gioia, 1992, p. 386).

After seeing pictures of a burnt car, Gioia experienced an emotional distress which made him call for a meeting in order to assess whether the Pinto cars should be recalled. However emotions are not usually part of a script, or they are internalised in such a way that they do not perturb the rational, analytical decision making process. As a whole person, reacting to both emotions and rational deliberations, Gioia perceived there was a problem with the car. However as a manager, compartmentalizing his emotions in order to perform according to a pre-defined script, Gioia (alongside his colleagues) failed to recognise the problem (Gioia, 1992). Their moral sensitivity for issues non-internalised by the script was switched off, therefore limiting their ability to make effective moral decisions. Gioia's "personal identity as captured in the revised script became much more corporate than individual." (1992, p. 387). The 'Ford manager' persona prevailed so that the ego-consciousness was alienated from the self, thereby preventing the self's moral authority from rising to consciousness.

Cases of moral myopia, moral muteness and lack of moral imagination equally echo the characteristics of compartmentalization. Drumwright and Murphy's (2004, p. 14) report on advertising practitioners' ethical perception revealed multiple cases of compartmentalization which "all resulted in the same effect. They permitted informants to avoid taking responsibility for negative effects of advertising." Actually, advertisers viewed compartmentalization as worth pursuing in order to stimulate creativity, defined as the "chief virtue" in the industry (Drumwright and Murphy, 2004). Yet it is neither possible nor acceptable to remove all ethical concerns for creativity's sake, because advertisers create something for a client to sell a given product to the public. Moral considerations are 
necessarily part of the creative process, but compartmentalization prevents advertisers from recognising this. It could be expected that instead of hampering creativity, embracing the moral values of the self would stimulate moral imagination and point towards new opportunities (Drumwright and Murphy, 2004).

Recent studies and testimonies, such as the examples cited above, have suggested that workplaces that welcome whole people (people who express emotions alongside rational thinking) are globally more creative and engaging (Guillory, 2001; Krishnakumar and Neck, 2002). Yet compartmentalization is still seen as a necessity for business success (Lovell, 2002). Ashar and Lane-Maher (2004) argue that this is symptomatic of the old business paradigm, as opposed to a more integrative, holistic model in construction. Figler and Hanlon (2008) also denounce this "psychological fragmentation" resulting from an excessive attention to rationality and logic, and the subsequent demise of subjectivity and of the unconscious sources that inform human relationships. In a study designed to explore the significance of the sense of self in moral experiences, I came across further evidence that compartmentalization prevails in management practice.

During a five-month period over 2006-2007, I interviewed twenty-five managers at all hierarchical levels, from first-line managers in large companies to CEOs of small-to-mediumsized enterprises. The research participants worked in various sectors ranging from IT services to recruitment to banking, both in France and Britain. The interviews were part of a larger research project, which aimed at exploring the significance of self in moral behaviour and moral deliberation processes. Each research participant was treated as a single case-study selected for their "explanatory power" (Mitchell, 2000, p. 180), and the interviews were semistructured to allow participants to speak freely about aspects relevant to them (Rubin and 
Rubin, 2005). Interviews were fully recorded, transcribed and analysed using an interpretive approach of gradual meaning-making and holistic content-analysis (Patton, 2002; Rubin and Rubin, 2005; Willis, 2007). Below are excerpts from the interviews with Amy and Vincent, which illustrate the tensions attached to compartmentalization (the names have been changed for reasons of confidentiality).

Amy, a Senior Account Manager for a direct marketing company, displayed typical traits of a person who does not really perceive that she compartmentalizes, although she alters her behaviour to suit the context. She believes she is her persona, thus clogging the expression and realisation of her full potential and her true self. At the same time, she rejects the feelings of empathy and compassion she experiences by rationalizing the situation 'as a business person would'. This leads her to work on potentially immoral accounts although her gut feelings would have been to refuse the assignment because she condemns the client's practices. In the following excerpts, Amy refers to one client financial company which offers loans to people with a poor credit history but charges very high interest rates - a barely legal activity from her own viewpoint. She admits that this company is involved in "hardly moral" schemes and that she would try her best to avoid working on that account because she disapproves of their questionable ethos. Yet, her moral integrity yields to her 'strictly business' persona:

I probably would refuse to do it. But then, because I'm so far removed with these people [...] because I don't see the actual effects it has on these poor people, it probably doesn't actually amass that much to me. Unless I can actually see what's happening, then it doesn't matter. [...] It's this kind of 'it's money, yeah, well, those people should work harder'. I'm that kind of person that thinks 'those people should work harder and earn more money, they shouldn't have gone into this situation anyway. If this is what they have to resort to, in order to get more 
money, well, that's their own fault' - a part of me is like that. So, yeah, I feel sorry for them 'you shouldn't be doing this', but actually [if] I owned that company, I would too.

So part of me feels like that, then I think 'okay, yes, some of these people - they really can't live on a day-to-day or a monthly paid wage, they do need that extra money every month just to help them', and that's why - I mean I worked for another client account for a little while, and that's what happened, so...but you know, they do, they just need $£ 200$ every month just to help them give in the credit card, just to help them, and then the next month they pay off, and then it goes on, and on and on. But you know, then they're just living...they're just spending more than they have. So that's not right, surely? You're encouraging them to do that. But then what? They're grown-ups, if they want to do that, let them do that! They're just silly!

Amy compartmentalizes so that her softer emotional self is discredited by her overwhelming “capitalist - you make your own money, you look out for yourself" persona, as she puts it. Consequently, her initial moral reluctance fades away which allows her to do her job efficiently. Yet Amy cannot help but feel that it is not quite right, no matter how well she embraces her persona. Besides, she contributes to legitimising morally questionable practices by rationalizing her moral concerns.

Vincent, on the other hand, fully acknowledges the fact that emotional distance does not alleviate his moral responsibility. Inasmuch as he tries to act professionally, he does his job with personal integrity. A field application engineering manager, Vincent suffers from what he calls the "loneliness of management"; he understands that a manager sometimes has to make difficult decisions and cannot rely on anyone else to deliver the news. However he genuinely cares for his team members not only because the team's performance improves, but also because he appreciates the contribution of each person on board. Vincent acknowledges 
that he "removes himself" at times when he has to face a difficult situation, for example laying-off staff. Yet, although he explains that he consciously takes time to set aside the emotional distress in order to 'do the job', he remains sensitive enough to consider the cost for the person at the receiving end. He may not be able to influence the decision, but he nevertheless acts with compassion and care that reflect his individual self. Vincent does not pretend to care; he really does care:

Telling somebody they no longer have a job [is difficult] [...] You begin to think about do they have a wife? Do they have children? Do they have, you know, large mortgage and bills to pay? Even if you try to remove yourself completely, that will still go across your mind at some point 'cause losing your job is a major life changing thing for most people. So from a morality perspective, you certainly think about it. Anybody who says they don't I would say is probably a liar.

$[\ldots]$

I certainly need to kind of sit and take a little bit of time before I actually get through with the action, and that bit of time is actually that time to sort of remove all the thoughts of "concern and why" out of my mind to actually focus on what needs to be done. So it's taking time to sort of reflect and be quite conscious of pushing some thoughts out of the way. Because it's clearly a function of 'this must be done and you need to execute that', albeit someone might say.

Vincent is acutely aware of his responsibility as a manager to respect the people he manages as people rather than as mere employees. During the interview, he was particularly concerned with the psychological cost of being made redundant. In the following excerpt, Vincent demonstrates a sense of personal responsibility for the way his actions affect others. He fully accepts the fact that he is an emotional being both at work and outside work. Vincent does not compartmentalize his emotions to make the process easier. Rather he embraces his 
individuality by integrating his emotional response into his behaviour as a manager. As a result, he acts with greater decency even if the end result remains the same (i.e. that staff has to be made redundant). Vincent enacts his personal moral values at work; this does not necessarily imply that he copes better with his managerial responsibility, but it nevertheless suggests that he feels more in line with himself at the end of the day.

No one likes to hear bad news, no one likes to be told bad news in a conflicting style if you like, or in an argumentative style or a very stern, you know 'your performance is absolutely terrible. Get out' - you know, you clearly can't say that from a HR perspective, but - in those terms, you know, very very negative. Erm...again, you know, if I - in the story where I have to lay off people, or let people go, the worst thing in the world is to literally take someone's morale down to a very very low level. It's a very very depressing thing losing your job. Thankfully I've never lost one but talking to friends who have, you know, there are huge things that go through people's minds. You know, how would I feel as a manager if I told someone that they didn't have their job and hours later they commit suicide that night? I would think about every word I've said to that individual, and whether the words I've said contributed to the action that they took. It sounds drastic but you kind of have to think about that... Clearly there are reasons why someone has to leave the company, whether be it financial or be it performance issue, etc. But there are ways you can break the news to them in a [...] more gentle fashion so that doesn't leave someone terribly depressed with the possible bad consequence.

- So you think it's almost a moral responsibility that you have in trying to be as nice as possible?

Yes. Would you fire somebody on a Friday? No, for then they have the weekend to think about it before they can talk to you about it again. You would fire them on a Monday or tell them they don't have a job on a Monday. But they have four weeks of notice to work, which means on Tuesday they can actually come and talk to you. The time of the week is important, you know. Do you know enough about your employee to say it's his birthday this week-end or his wedding 
anniversary or you know - if you know enough about that and there's something consequential coming along, you'd actually say 'd'you know what, I'm not going to do it then, I'm gonna push to try to do it a few days later.' Don't ruin a particular special occasion. Sounds maybe a little bit oversensitive but at the same time you just try to think 'don't ruin something completely for somebody'.

\section{- And when you don't know the people?}

It's a lot easier to fire them, you don't need necessarily to think about that, it's less hard 'cause you don't know the details. In my last company, we - I was involved, but ultimately we laid off 20 staff on the last day before Christmas. Personally, I think it was a really nasty thing to do. I think if it was me and I was able to make the decision, I would have all let them have a nice Christmas and on the first day back in January, given them the news. Because what's a worse way to spend Christmas than to hear you have no job, you've just spent all your money on presents and everything else for the kids and the family, and you probably end up worrying the entire Christmas. And trying to find a job at Christmas time is not that easy, everyone's gone on holiday, so...that's me!

Over time, Vincent not only builds his moral strength through moral integrity and consistency, but he also re-shapes his managerial role to integrate his higher moral standards. On the contrary, compartmentalized people accommodate their moral values and sense of self to suit the role expectations or the environment's demands.

\section{Conclusion}

Compartmentalization is a fact of life, especially when it comes to separating our professional actions from our personal aspirations. We generally argue that we do not have a choice but to do what we personally condemn, that business or the workplace forces us to change our values, that psychological fragmentation ultimately keeps us sane and enables us to enjoy life in spite of our uneasiness at work. In brief, we survive because we compartmentalize. This 
paper has argued that this picture fails to consider the moral implications of compartmentalization. In particular, compartmentalization cancels the possibility to ascribe personal responsibility to an individual and only provides a temporary and superficial relief from pain and distress. More importantly, it limits our ability to connect to our values, to be moral agents, and to act with moral courage and moral integrity.

Jung argues that the ultimate purpose of a human life is to achieve individuation, a state of complete transcendence of our dualities and full manifestation of our individuality. In order to achieve individuation, one must embark on a quest for self-knowledge, confronting selfdeception and accepting the burden of our shortcomings. Compartmentalization prevents selfknowledge by allowing fragmentation of the individual, depriving us from the most important source of moral strength we possess: the self, our self. Embracing wholeness and seeking integrity by refusing to yield to the compartmentalization temptation is beneficial to both the individual and society at large. Organisations can change, but only if the people who work in them accept the challenge of wearing no more masks and just being their self.

\section{$\underline{\text { References }}$}

Aïssel, S.: 2005, La Nouvelle Psychologie Spirituelle, (Spiritual Book France, Barr)

Ashar, H. and Lane-Maher, M.: 2004, 'Success and Spirituality in the New Business Paradigm', Journal of Management Inquiry 13(3), 249-260.

Colman, W.: 2008, 'On Being, Knowing and Having a Self', Journal of Analytical Psychology 53(3), 351-366.

Crowley, V.: 1998, Principles of Jungian Spirituality, (Thorsons/HarperCollins, London). 
Doron, R. and Parot, F.: 1991, Dictionnaire de Psychologie, (Presses Universitaires de France, Paris).

Drumwright, M.E. and Murphy, P.E.: 2004, 'How Advertising Practitioners View Ethics', Journal of Advertising 33(2), 7-24.

Elster, J. (ed.): 1986, The Multiple Self, (Cambridge University Press, Cambridge).

Ferrucci, P.: 2004, What we may be, (Jeremy P. Tarcher/Penguin, New York, NY).

Figler, R. and Hanlon, S.: 2008, 'Management Development and the Unconscious From an Analytical Psychology Framework', Journal of Management Development 27(6), 613-630.

Flores, A. and Johnson, D.G.: 1983, 'Collective Responsibility and Professional Roles', Ethics 93(3), 537-545.

Gioia, D.A.: 1992, 'Pinto Fires and Personal Ethics: A Script Analysis of Missed Opportunities', Journal of Business Ethics 11(5/6), 379-389.

Goffman, E.: 1959, The Presentation of Self in Everyday Life, (Penguin, Harmondsworth).

Gotsis, G. and Kortezi, Z.: 2008, 'Philosophical Foundations of Workplace Spirituality: A Critical Approach', Journal of Business Ethics 78(4), 575-600.

Guillory, W. A.: 2001, The Living Organization - Spirituality in the Workplace, 2nd edition (Innovations International, Salt Lake City, UT).

Hall, C.S. and Nordby, V.J.: 1973, A Primer of Jungian Psychology, (Meridian Book/Penguin, New York, NY).

Hill, R.D.: 2000, Self Discovery: The Spiritual Psychology of C.G. Jung, (AmErica House Book Publishers, Baltimore, MD).

Hubback, J.: 1998, 'The Dynamic Self’, Journal of Analytical Psychology 43(2), 277-285.

Jung, C.G.: 1958/2002, The Undiscovered Self, (Routledge, London). 
Jung, C.G.: 1969a, Aion - The Collected Works Vol.9 Part II, 2nd edition (Princeton University Press, Princeton, NJ).

Jung, C.G.: 1969b, Psychology and Religion: East and West - The Collected Works Vol.11, 2nd edition (Routledge \& Kegan Paul, London).

Jung, C.G.: 1971, Psychological Types - The Collected Works Vol.6, (Routledge London).

Kelly, B.: 1998, 'Preserving Moral Integrity: A Follow-up Study with New Graduate Nurses', Journal of Advanced Nursing 28(5), 1134-1145.

Krishnakumar, S. and Neck, C.P.: 2002, 'The 'What', 'Why' and 'How' of Spirituality in the Workplace', Journal of Managerial Psychology 17(3), 153-164.

La Bruyère, J.: 1688/1975, Les Caractères, (Folio/Flammarion, Paris).

Layder, D.: 2004, Social and Personal Identity: Understanding YourSelf, (Sage, London).

Lovell, A.: 2002, 'Moral Agency as Victim of the Vulnerability of Autonomy', Business Ethics: A European Review 11(1), 62-76.

MacIntyre, A.: 1999, 'Social Structures and their Threats to Moral Agency', Philosophy 74, 311-329.

Mitchell, J.C.: 2000, 'Case and Situation Analysis', in R. Gomm, M. Hammersley and P. Foster (eds.), Case Study Method (Sage, London), pp.165-186.

Monte, C.F.: 1997, Beneath the Mask: An Introduction to Theories of Personality, 6th edition (Harcourt Brace, Forth Worth, TX).

Moss, T. and Carr, T.: 2004, 'Understanding Adjustment to Disfigurement: The Role of the Self-Concept', Psychology and Health 19(6), 737-748.

Pajak, E.F. and Blase, J.J.: 1984, 'Teachers in Bars: From Professional to Personal Self', Sociology of Education 57(3), 164-173.

Patton, M.Q.: 2002, Qualitative Research and Evaluation Methods, 3rd edition (Sage, Thousand Oaks, CA). 
Pratt, M.G. and Foreman, P.O.: 2000, 'Classifying Managerial Responses to Multiple Organizational Identities', The Academy of Management Review 25(1), 18-42.

Rousseau, J.-J.: 1761/1999, La Nouvelle Héloïse, (Garnier Flammarion, Paris).

Rubin, H.J. and Rubin, I.S.: 2005, Qualitative Interviewing: The Art of Hearing Data, 2nd edition (Sage, Thousand Oaks, CA).

Sharp, D.: 1991, Jung Lexicon - A Primer of Terms \& Concepts, Available at: http://www.cgjungpage.org [Accessed 05/07/07].

Showers, C.J. and Zeigler-Hill, V.: 2007, 'Compartmentalization and Integration: The Evaluative Organization of Contextualized Selves', Journal of Personality 75(6), 1181-1204.

Terestchenko, M.: 2007, Un Si Fragile Vernis d'Humanité - Banalité du Mal, Banalité du Bien, (La Découverte/Poche, Paris).

Terestchenko, M.: 2008, 'On s'y habitue', La Chronique 254, 15.

Vice, S.: 2003, 'Self-reflection and the Worthwhile Life', Unpublished PhD Thesis, University of Reading, Reading.

Werhane, P.H.: 1999, Moral Imagination and Management Decision-Making, (Oxford University Press, New York, NY).

White, S. L.: 1991, The Unity of the Self, (Bradford Book/MIT Press, Cambridge, MA).

Willis, J.W.: 2007, Foundations of Qualitative Research - Interpretive and Critical Approaches, (Sage, Thousand Oaks, CA).

Zsolnai, L.: 2004, 'Spirituality and Management', in L. Zsolnai (ed.), Spirituality and Ethics in Management, (Kluwer Academic Publishers, Dordrecht), pp. 3-12. 